\title{
A Study to Examine the Association of Health Related Behaviours and Body Mass Index among Young Adults at Selected Colleges in Kancheepuram District, Tamil Nadu, India
}

\author{
J.Sherlinblessy ${ }^{1}$, G.Santhiya ${ }^{1}$, E.Mohan1, Shanthi ${ }^{2}$ \\ ${ }^{1}$ IIIrd Year B.Sc Nursing Students, ${ }^{2}$ Guide and Co-investigator, Professor, Medical Surgical Nursing Department, \\ Chettinad College of Nursing, Chettinad Academy of Research and Education, Rajiv Gandhi Salai, Kanchipuram \\ district, Tamil Nadu, India
}

\begin{abstract}
A observational study to examine the association of Health related behaviours and Body mass index among young adults at selected colleges in Kanchipuram District, Tamil Nadu, India". The objectives were to examine the lifestyle practices and Body mass index among young adults at Kanchipuram district, Tamil $\mathrm{Nadu}$ and to find out the association between lifestyle practices and BMI with demographic variables. The convenience sampling was used to select 100 young adults. The data collection tools were validated and reliability was established. The data were collected by self-administered questionnaire. The collected data was Tabulated and Analyzed. Descriptive and Inferential statistical methods were used. The study shows that of the higher frequency of 18-24 years (96\%) and lower frequency of 20-24 years (4\%). In Gender, Male is lowest frequency $(28 \%)$ and Female is the highest frequency $(72 \%)$. There was significant association between the knowledge and the selected demographic variables.
\end{abstract}

Keywords :Health related behaviour, Body mass index, Young Adults.

\section{Introduction}

Majority of Indian population lives in rural areas mainly depending on agriculture for their livelihood and carry out more physical activities than urban population, who are accustomed to sedentary lifestyle1. Diet is a component of lifestyle, which plays an important role in the development or prevention of overweight and obesity.Young people brought up in rural areas lead a healthier life style compared to their peers in big cities². Physical activities changed as a result of increased television watching, spending more time on computer or mobile and spending less time on outdoor sports. The

\section{Corresponding Author:}

J.Sherlinblessy

IIIrd Year B.Sc Nursing students, Chettinad College of Nursing, Chettinad Academy of Research and Education, Rajiv Gandhi Salai, Kanchipuram district, Tamil Nadu, India

Email: sherlinbj422@gmail.com dysregulation of energy consumption and expenditure related to inappropriate dietary habits and lack of exercise increases the prevalence of both overweight and obesity ${ }^{3}$.

Young people form precious human resources in every country. However, there is considerable ambiguity in the definition of young people and terms like young, adolescents, adults, young adults are often used interchangeably. World Health Organization (WHO) defines 'adolescence' as age spanning 10 to 19 yr, "youth" as those in 15-24 yr age group and these two overlapping age groups as "young people" covering the age group of 10-24 yr4. Adults include a broader age range and all those in 20 to $64 \mathrm{yr} 5$. Adolescence is further divided into early adolescence (11-14 yr), middle adolescence (15-17 yr), and late adolescence (18-21 yr)6. Individuals in the age group of $20-24 \mathrm{yr}$ are also referred to as young adults7. The National Youth Policy of India (2003) defines the youth population as those in the age group of 15-35 yr8. 
Population aged 10-24 years accounts for 373 million (30.9\%) of the 1,210 million of India's population with every third person belonging to this age group. Among them, 110 and 273 million live in urban and rural India, respectively. Males account for 195 million and females 178 million, respectively9. As per the National Sample Survey (NSS), (2007-08) 32.8 per cent of this group attend educational institutions and 46 per cent (2004-05) are employed ${ }^{10}$.

Obesity can arise in early years due to irregularity in diet, lack of exercise and addiction. The young students who live away from home in hostels are more prone tohave unhealthy lifestyle. Unhealthy diet and physical Inactivity at younger ages are the two main risk factors that have been associated with raised blood pressure ,blood glucose, abnormal blood lipids, major chronic disease like ischemic heart disese, cancer, and diabetes. India is encountering a dual burden of under nutrition over nutrition due to monetary factors and education of the people of society. There are many factors which influence BMI among adolescents and young adults. Thus ,the present study was done to assess the Health behaviour and BMI among students of a Nursing college in Chennai.

\section{Resaerch Materials and Method}

Research Approach:

A research approach is a frame work or guide used for the planning, implementation and analysis of the study. It also involves the plan to investigate the phenomenon under study.

Quantitative descriptive approach.

\section{Research Design:}

The research design is the master plan specifying the methods and procedures for collecting and analyzing the needed information in a research study.

A sample of 100 students was selected for the study by using convenient sampling method. The instruments used for data collection were structured questionnaire's to determine height, weight and BMI.

The investigator plan to collect the data for the period of one week. Prior permission and consent was obtained from the Hindu mission college of nursing.

Chi-square test was used to find out the association between demographic variables of health related behaviour and body mass index.

Research Setting:

A research setting is a physical social and cultural site in which the researcher conducts the study.

The present study was conducted at Hindu mission nursing college, Tamilnadu, India.

Population

Population is the aggregation of all units in which a researcher is interested in other words, Population is a set of people or entities to which the result of a research are to be generalised .

Data related to lifestyle practices and body mass index among young adolescents was obtained from Hindu mission college students .

The population of the study is college students.

Sample :

Sample is a representative unit of a target population , which is to be worked upon by the researchers during their study. In other words sample consists of subsets of units which comprise the population selected by the researcher to participate in the research project.

The sample are the students who are fulfilling the sampling criteria.

Sample Size : Sample size was 100. N-4pq/d.

Sample Techniques

Sampling Criteria:

A) Inclusion criteria.

The study include the college students including aged between 18-24 years.

$\S \quad$ Who are willing to participate in the study.

$\S$ Who can understand Tamil and English language.

B) Exclusion criteria.

$\S$ who are not willing to participate in the study. Those

$\S$ Those who are absent on the day of data 
collection.

SELECTING AND DEVELOPEMENT OF THE STUDY INSTRUMENT

SECTION A:Demographic Variables such as .

\section{SECTION B:}

PART a: Anthropometric Measurement (Height ,weight and BMI) with the help of the stadiometer and weighing scale.

PART b: Structured life style Questionnaire to assess the young adults health related behaviors.

Scoring Interpretation:

\section{Data Collection Method}

Data collection was done after the approval of ethical committee. The investigator approached and got permission from principal college of nursing to collect the baseline data to Weight was recorded for each girl and boy with school uniform, with the each girl/boy standing erect without any support and without shoes using an electronic weighting scale to an accuracy of $0.1 \mathrm{Kg}$. Height was taken with the help of a stadiometer after removing the footwear with the subject standing erect and heel and occiput touching the upright rod to the nearest $0.5 \mathrm{~cm}$. Weight was measured to nearest $100 \mathrm{gms}$. Using the weight and height, Body mass index (BMI) was calculated in $\mathrm{Kg} / \mathrm{m} 2$, for each girl and boy using standardized CDC BMI chart for boys and girls. Based on age and sex specific BMI centiles, the children were classified as overweight ( $\geq 85$ th centile) and obese ( $\geq 95$ th centile) and non-overweight and non-obese ( $<85$ th centile) .Initial data was collected on demographic and clinical variables and then structured Lifestyle questionnaire was given to the group.

\section{Ethical Consideration:}

Departmental clearance obtained from Department Of Medical Surgical Nursing, Chettinad college of Nursing.

U .G committee clearance will be obtained from U.G committee.

Institutional Ethical Committee clearance will be obtained from CARE.

Formal permission will be obtained from the authority of the selected college Authority.

- Informed consent will be obtained from the study samples.

\section{FINDINGS}

The study findings are categorized as:

SECTION A : Describe the frequency and percentage of demographic variables

SECTION B: Association of demographic variables with the lifestyle practices and body mass index

SECTION C: Distribution of Correlation between the lifestyle practices and body mass index.

\section{SECTION - A}

Frequency Percentage of Demographic Variables In Lifestyle Practices And Bmi Among Young Adolescents

Majority of young adolescents were in age group of $96 \%$ in $18-20 y r s$ and only $4 \%$ takes place in $21-23 y r s$.

7In Gender, female takes place of $72 \%$ more than males of $28 \%$.

Distribution of percentage in undergraduate students of each year is 24\% in I year,34\% in II year,36\% in III, $6 \%$ in IV year.

Residency of student in hostel is $41 \%$ and dayscholar is $59 \%$.

- Source of information were available through Health professionals is $36 \%$, Mass media is $40 \%$ and relatives/ friends is $24 \%$. Dietary habits of nonvegetarian is $91 \%$ more than $9 \%$ of vegetarian

SECTION B: Association of demographic variables with the lifestyle practices and body mass index

Describes that in age group 18-20years in underweight is $35 \%$,normal is $51 \%$ and overweight is $10 \%$, in $21-23$ years underweight is $0 \%$,normal is $3 \%$ and overweight is $1 \%$.

Distribution of gender in underweight for male is $15 \%$,normal is $13 \%$ and overweight is $0 \%$ and for female in underweight is $20 \%$,normal is $41 \%$ and overweight is $11 \%$.

Hostellers in underweight is $13 \%$, normal is $23 \%$ and overweight is $5 \%$ and dayscholars in underweight is 
$22 \%$, normal is $31 \%$ and overweight is $6 \%$.

Dietary habits of adolescents to vegetarian in underweight is $3 \%$,normal is $4 \%$ and overweight is $2 \%$ and in non-vegetarian in underweight is $32 \%$,normalis $50 \%$ and overweight is $9 \%$.

\section{SECTION - C}

TABLE 1- Correlation between lifestyle practices and Body mass index .

\begin{tabular}{|l|l|l|l|}
\hline VARIABLES & MEAN & STANDARD DEVIATION & CORRELATION (r2) \\
\cline { 1 - 3 } Practice & 5687 & 56.87 & \multirow{2}{*}{0.02} \\
\cline { 1 - 3 } BMI & 2018.7 & 20.187 & \\
\hline
\end{tabular}

TABLE 1 shows that there is a statistically mild positive correlation occurs between the lifestyle practices and body mass index.

\section{Conclusion}

All health behaviours exhibited independent associations with lifestyle practices and body mass index. Frequent consumption of vegetables and fruits, breakfast and dinner with family and regular physical activity were positively associated with good levels of lifestyle practices and BMI, while frequent consumption of junk food, not meeting sleep recommendations, and overweight and obesity were negatively associated lifestyle practices and BMI achievement.

\section{Conflict of Interest : Nil}

\section{Source of Funding : Self}

Ethical Clearance : Chettinad academy of research and education, institutional human ethics committee on 4/02/2019 ( Proposal No :328/IHEC/1-19)

\section{References}

1. Saha GC, Haldar S. Comparison of Health Related Physical Fitness Variables And Psychomotor Ability between Rural and Urban School Going Children. J Exercise Sci Physiotherapy 2012; 8: 105-108.

2. Suliburska J, Bogdanski P, Pupek-Musialik D, Glod-Nawrocka M, Krauss H, Piatek J. Analysis of lifestyle of young adults in the rural and urban areas. Annal Agricultural Environmental Med 2012; 19: 135-139.

3. Majeed F. Association of BMI with diet and physical activity of female medical students at the university of Dammam, Kingdom of Saudi Arabia. J Taibah University Med Sci 2015; 10: 188-196.

4. Adolescenthealth and development. WHO Regional office for South-East Asia. [accessed on January 8, 2013]. Available from: http://www.searo.who.int/ entity/child_adolescent/topics/adolescent_health/ en/index.html .

5. World Health Organization. The World Health Report 1998. Life in the 21st Century. A vision for all. Report of the Director-General. Chapter 3. Geneva: World Health Organization; 1998. [accessed on January 8, 2013]. Health across the life span; pp. 66-111. Available from: http://www. who.int/whr/1998/en/whr98_en.pdf .

6. Stang J, Story M. Chapter 1. Adolescent growth and development. Guidelines for adolescent nutrition services. Minneapolis, MN Center for Leadership, Education and Training in Maternal and Child Nutrition, Division of Epidemiology and Community Health, School of Public Health, University of Minnesota. 2005. [accessed on June 20, 2012]. Available from: http://www.epi.umn. edu/let/pubs/img/adol_ch1.pdf .

7. Jekielek S, Brown B. Kids count/PRB/Child Trends Report on Census 2000. The Annie Casey Foundation, Population reference Bureau, and Child trends, Washington DC; 2005. May, [accessed on June 20, 2012]. The Transition to Adulthood: Characteristics of Young Adults Ages 
18 to 24 in America. Available from: http://www. prb.org/pdf05/transitiontoadulthood.pdf .

8. Planning commission. New Delhi: 2008. Sep, [accessed on June 18, 2012]. Report of the Steering committee on youth affairs and sports for the eleventh five year plan (2007-12) p. 41. Available from: http://planningcommission.nic.in/aboutus/ committee/strgrp11/str_yas.pdf .

9. National Health Profile 2011. New Delhi: Prabhat Publicity; 2011. [accessed on June 18, 2012].
Central Bureau of Health Intelligence. Demographic indicators. Available from: http:/www.cbhidghs. nic.in/writereaddata/mainlinkFile/01\%20 Cover\%20page\%202011.pdf .

10. Dev SM, Venkatanarayana M. Mumbai: indira Gandhi Institute of Development Research; 2011. [accessed on December 28, 2012]. Youth employment and unemployment in India. Available from: http://www.igidr.ac.in/pdf/publication/WP2011-009.pdf. 